\title{
FRUIÇÃO, PROXIMIDADE E VULNERABILIDADE: A CONSTITUIÇÃO DA SUBJETIVIDADE ÉTICA DOCENTE A PARTIR DE E. LEVINAS
}

\author{
Genivaldo de Souza Santos
}

Instituto Federal de Educação, Ciência e Tecnologia de São Paulo - IFSP, Birigui, SP. E-mail: genivaldo@ifsp.edu.br. Grupo de estudo e pesquisa em Ética, Educação e Sociedade.

\section{RESUMO}

O presente artigo é fruto das reflexões e pesquisas realizadas no GEPEES - Grupo de Pesquisa Ética, Educação e Sociedade, desenvolvidas na UNESP (Campi Assis e Marília). Por meio de análise bibliográfica, pretendemos problematizar o lócus da sensibilidade na constituição da subjetividade docente no campo da ética. Pretendemos alimentar um debate que visa resgatar o elemento da sensibilidade em seu sentido ético através do pensamento do filósofo judeu franco lituano Emanuel Levinas, para quem ética significa o encontro sensível com a alteridade, configurado sob os signos da fruição, da aproximação e da vulnerabilidade. Trata-se de uma perspectiva ética que se converte em posicionamento político, na medida em que ao realizarmos o giro ético proposto por Emanuel Levinas, as pretensões de dominação e assimilação (totalização) características da estrutura do Eu são constantemente questionadas. Tais pretensões também se manifestam na cultura, em que pese o lugar de precedência do Eu em relação ao Outro.

Palavras-chave: Sensibilidade, Ética, Subjetividade, Levinas, Educação.

\section{THE LOCUS SENSITIVITY IN ETHICAL PHENOMENON: REFLECTIONS FROM KANT AND LEVINAS.}

\begin{abstract}
This article is the result of the reflections and research carried out at the GEPEES - Ethics, Education and Society Research Group, developed at UNESP (Campi Assis and Marília). Through bibliographical analysis, we intend to problematize the locus of sensitivity in the constitution of teaching subjectivity in the field of ethics. We intend to nourish a debate that seeks to rescue and problematize the element of sensibility in its ethical sense, through the thought of the FrancoLithuanian Jewish philosopher Emanuel Levinas, for whom ethics means the sensitive encounter with otherness, configured under the signs of fruition, approximation and vulnerability. It is an ethical perspective that becomes a political position, inasmuch as in carrying out the ethical turn proposed by Emanuel Levinas, the pretensions of domination and assimilation (totalization) characteristic of the structure of the Self are constantly questioned. Such pretensions also manifest themselves in culture, in spite of the place of precedence of the Self in relation to the Other.
\end{abstract}

Keywords: Sensitivity, Ethics, Kant, Levinas, Education. 


\section{INTRODUÇÃO}

As reflexões que seguem são oriundas dos debates e do contínuo exercício de interrogação realizado pelo GEPEES - Grupo de Estudo e Pesquisa Ética, Educação e Sociedade sobre o lugar e a importância da ética nos contextos educativos. Especificamente sobre o lócus da sensibilidade no fenômeno ético, compreendendo sensibilidade em sua conexão com o corpo e com as paixões.

Esta dimensão sensível a que nos referimos pode ser compreendida no registro aristotélico do pathos, isto é, da paixão, como elemento que nos co-move, nos levando a ação e neste sentido constituindo uma Ética, como o domínio das atitudes e das ações humanas e que diferentemente do conhecimento exato e consequente produzido pela episteme/ciência, tem que decidir face ao imponderável, ao imprevisto, ao inconsequente, enfim face às contingências inerentes à existência. Em linhas gerais, trata-se de uma mudança de foco em relação a Platão, que desprezando a sensibilidade, acentuou a importância da razão, entendido como racionalidade lógica e matemática, na constituição da subjetividade e da ética.

Desde a filosofia clássica, portanto, percebemos a instauração de uma tensão entre razão e sensibilidade e pela busca do justo lugar de cada qual no fenômeno humano, cujos desdobramentos chegam até nós com força renovada, tendo em vista a densidade dos dilemas éticos vivenciados contemporaneamente e nossa recente e constante história de violência e dominação, que por sua vez, exigem respostas éticas.

Uma das vozes mais radicais de nosso tempo que reivindicam um justo lugar para a sensibilidade na constituição do fenômeno ético é a do filósofo lituano Emanuel Levinas (19051995), cujas considerações emergem de sua experiência concreta nos campos de concentração nazista e de seu testemunho de duas guerras mundiais, sendo que em uma delas participou diretamente como soldado.

Face a violência promovida pela guerra e pelo regime nacional socialista de Hitller, a resposta filosófica de Levinas não é a do rancor e do ressentimento, como poderíamos esperar, mas nos aponta para do rosto do Outro e de sua inalienável importância na constituição da posição de sujeito, isto é da subjetividade.

Embora a filosofia moderna, especialmente com Imanuel Kant, tenha estabelecido as bases formais de constituição da subjetividade, trata-se de uma formulação que afirma a autonomia como elemento fundante na constituição do sujeito, em um movimento de pensamento em que Outro assume uma posição secundária. Contrariamente, para Levinas, não é o sujeito autônomo que constitui a alteridade, em outras palavras, não é o sujeito que vem em primeiro lugar e que dá as condições de emergência do Outro. Para ele, o Outro vem em primeiro lugar e desse encontro com o Outro é que são dadas as condições de emergência de uma subjetividade com contornos éticos.

Para um melhor esclarecimento, em termos gerais, a formulação ética kantiana impõe ao homem uma tarefa: esclarecer-se a si mesmo, ter coragem para fazer uso de seu entendimento, alcançar a maioridade e pensar por si mesmo. A vontade e a sensibilidade não podem conduzi-lo a esta vida autônoma, haja vista que são do domínio da dependência externa, circunscrevem-se nos domínios do pathós, no reino das paixões (ANDRADE, 2013).

$\mathrm{Na}$ perspectiva levinasiana, o sensível somente pode ser visto como superficial quando subordinado ao conhecimento, pois, entendido na perspectiva da relação ética, na sua relação de contato e proximidade, o sensível cumpre sua função essencial. É nessa relação de contato e proximidade com o Outro, que o sensível pode ser considerado como um elemento capaz de tecer uma nova relação ética com o próximo.

A partir destas considerações iniciais e assumindo a sala de aula como lócus privilegiado para uma reflexão a respeito da ética em sua conexão com a educação a questão que mobilizou nosso pensamento e que para nós é importante de ser pensada, dada suas implicações na compreensão das relações reais e concretas que são estabelecidas em contextos educativos, pode 
ser traduzida do seguinte modo: quais as possíveis consequências do giro ético levinasiano, que ocorre quando a posição de sujeito é precedida pelo Outro via sensibilidade (e não através da formalidade de uma razão autônoma kantiana), nos contexto educativo?

Adotamos a abordagem qualitativa orientada pela hermenêutica dos textos de Emanuel Levinas e dos seus comentadores. Embora consideremos que a filosofia levinasiana pode e deve ser estudada, seu sentido estaria incompleto se este estudo não ajudar a responder os apelos que vêm do Rosto do Outro, especialmente aquele Outro que é sistematicamente silenciado por sua capacidade perturbadora em relação às pretensões totalitárias do Eu/Mesmo.

Para Levinas (1980), a história da Filosofia, desde Parmênides até Heiddeguer, ao conferir primazia às especulações sobre o Ser, esqueceu-se de algo mais originário e mais determinante, que é o encontro com a Alteridade. O esquecimento deste encontro com o rosto do Outro constituiu uma filosofia marcada pela violência e o desenvolvimento de uma civilização orientada para a guerra, promovida pela ideia de Totalidade, que busca a todo custo assimilar, submeter, dominar a alteridade do Outro, que sempre escapa, por sua natureza, às totalizações e domínios.

Os resultados desta pesquisa, realizada junto ao GEPEES - Grupo de Pesquisa Ética, Educação e Sociedade, durante os anos de 2015-2017, apontam que o giro ético necessário ao exercício de uma ética levinasiana nos conduz a uma problematização de cunho essencialmente política, ao questionar as tentativas de dominação do Mesmo em relação ao Outro, de modo a deslocar os lugares de precedência do Eu e do Outro.

\section{SUBJETIVIDADE COMO FRUIÇÃO, PROXIMIDADE E VULNERABILIDADE EM E. LEVINAS.}

A concepção levinasiana de Alteridade guarda um vínculo embrionário com uma noção de "sensibilidade carnal", pois antes de emergir qualquer "sentido" ocorre o encontro face a face. Apenas, a partir deste encontro original entre os humanos é que pode emergir as possibilidades de sentido. Diante do "rosto" do Outro é que o "eu" se descobre como subjetividade ética, irrevogavelmente responsável, visando reconstruir uma subjetividade não centrada tanto no "eu", porém centrada na estrutura "um-para-o-outro", descrita nos termos do "acolhimento e da responsabilidade".

Inicialmente, em Totalidade e Infinito, talvez a principal obra de Levinas, a sensibilidade é descrita como fruição dos elementos do mundo, não pertencente à ordem do pensamento, da representação dos objetos, mas à ordem do sentir. Esta é a nossa primeira relação com o mundo, pois como afirma Levinas (1980, p. 123) "[...] fruímos do mundo antes de nos referirmos aos seus prolongamentos: respiramos, caminhamos, vemos, passeamos etc..." . Como fruição, a sensibilidade é assumida não como um elemento subordinado ao entendimento (MIRANDA, 2011, p. 172), mas é situado na ordem do sentimento, do sentir a plenitude da fruição, por ela, "acolhemos" os elementos do mundo sem, no entanto, pensarmos neles.

Entretanto, acima da fruição esboça-se o pôr em comum - um discurso sobre o mundo, nos termos da apropriação e da representação, acrescentando um novo acontecimento à fruição (LEVINAS, 1980, p. 123), em outras palavras, há a inscrição da linguagem que se coloca como uma representação que inicia um novo movimento na constituição da subjetividade ética.

Assim, o mundo, além de alimento que fruimos torna-se uma representação do eu. Entretanto, é na irrupção do rosto do Outro que se inaugura uma nova relação com a alteridade. 0 traumatismo do eu provocado pela epifania do rosto do Outro é o que inscreve um sentido ético na sensibilidade, como acolhimento e responsabilidade ao Outro (um-para-o-outro), um primeiro na constituição da subjetividade ética.

O Próximo é compreendido como o Outro, que surge como rosto, cujo significado antecede à representação que fazemos dele. Deste modo, o rosto é compreendido como significância ética, surgindo como o elemento novo capaz de produzir um traumatismo no eu e inscrevendo no bojo da sensibilidade o acolhimento e a responsabilidade ao outro o sentido ético da subjetividade. 
Sobre a questão das representações que fazemos do Outro no registro das relações humanas, Moyses Neto, ainda que por sua força ilustrativa, nos ajuda a compreendê-las, ao dizer de maneira bastante coloquial, que reproduzo a seguir: "Qualquer pessoa com experiência afetiva e um pouquinho de inteligência sabe que não existe beco mais sem saída do que uma relação em que não existe respeito pela alteridade do outro. Não existe maior armadilha do que a representação. Quer ser infeliz no amor? (traduzindo para o campo pedagógico: Quer ser infeliz nas relações pedagógicas?) Simples: basta, ao conhecer uma nova pessoa, colocar nela a realização de todos os seus desejos e ficar imaginando que irá a transformar na pessoa ideal (ou no aluno ideal). "Ela tem tudo para ser exatamente como eu gostaria que fosse minha mulher!". "Ele é um pouco ..., mas em breve será o homem ideal!". Fracasso certo. Não vai funcionar. Ao aceitar outra pessoa, precisamos inicialmente começar pela diferença, se não a coisa não tem qualquer chance de funcionar. Aquela imagenzinha escondida na nossa cabeça -- a "mulher ideal", o "homem perfeito", ("o aluno ideal") -- são representações. E representações só existem enquanto tal; no mundo real, o que existe é brutalidade do real (ou seja, a alteridade). O outro (o outro do professor) não é o que eu penso que ele é, nem quer ser. Se tentar, vai sofrer um monte. Os dois, aliás. Se começo uma relação acreditando que posso mudar o outro, não comecei nada. Já comecei com violência; é uma relação natimorta. O "passado" sadio foi imediatamete engolido por uma estrutura que já começou corrompida. E, por isso, vemos tanta gente sofrendo, desesperada para "salvar a relação", ou, pior, incapaz de desistir do seu projeto. Sob esse prisma, a ética da alteridade tem toda razão." (MOYSES NETO, 2016, itálico e intervenção nossa)

A sensibilidade como contato e proximidade com o Outro, é, antes de representação, concebida nos termos de "acontecimento de proximidade". Para Levinas o próximo não segue "a medida e o ritmo da consciência" (LEVINAS, 1998, p. 280); não é definido a partir de uma categoria conceitual, na qual sua alteridade é desde já neutralizada, pois o "Próximo é precisamente aquilo que tem o sentido imediatamente, antes de lhe conferirmos". (LEVINAS, 1998, p. 279)

Para o filósofo franco-lituano, aproximar-se do Outro significa sentir, tocar, entrar em contato com o próximo, situa-se além da mediação conceitual e dos dados apreendidos à distância no conhecimento (MIRANDA, 2011). Consiste, nos termos definidos por Levinas (1998, p. 287) “[...] em aproximar-se de Outrem, mantendo uma relação não alérgica à sua irredutível alteridade [...] esta transformação do dado em próximo e da representação em contato, o saber em ética, é rosto e pele humana". É a partir da relação de proximidade entre o Eu e o Outro que o discurso é Inaugurado, pois "seja qual for a mensagem transmitida pelo discurso, o falar é contato" (LEVINAS, 1998, p. 274).

Trata-se de uma compreensão ética que promove uma inversão da relação entre a subjetividade e a alteridade, pois a subjetividade ao entrar em contato com a singularidade do Outro, anula sua identificação do Outro com um ideal, não tematiza a alteridade como uma representação, mas encontra-se face a face com uma singularidade absoluta e como tal irrepresentável. Para Levinas, aí está a linguagem original, fundamento do Outro.

No contato com o próximo instala-se uma inquietude que se produz como um traumatismo, sentida pelo humano na pele exposta da sensibilidade, e não pensada abstratamente por meio da razão. Assim, o segundo momento da inscrição da sensibilidade no fenômeno ético surge em Levinas em sua obra De otro modo que ser o más allá de la esencia (1974), em que a sensibilidade é pensada em termos de fruição (gozo) e de ferida (sofrimento) na relação de proximidade, vindo a constituir uma subjetividade caracterizada como vulnerabilidade.

Estruturada por tais elementos, trata-se de uma subjetividade descrita na forma de completa passividade que exposta à Alteridade expressa a vulnerabilidade da sensibilidade, em um sentido de doação do próprio pão que se come como conversão do gozo em resposta ética face o rosto do Outro. Mas como alerta Levinas (2003), para que o sentido ético da doação aconteça, "é 
necessário previamente gozar de seu próprio pão, não a fim de ter o mérito de dá-lo, senão para dar com ele o seu coração, para dar-se no ato de dá-lo. O gozo é um momento inevitável da sensibilidade" (MIRANDA, 2011, p. 178).

Trata-se de uma concepção de sensibilidade, descrita nos termos de fruição (gozo), contato (proximidade), vulnerabilidade (exposição, ferida, sofrimento), sem os qual não haveria fenômeno ético, constituindo-se em elemento de base da própria subjetividade, que inscrita no seio da intriga ética entretece a relação face-a-face com o Outro.

Neste sentido, a subjetividade encontra, na sensibilidade, a via primordial de relação com o Outro, via construída não a partir da representação do Outro, mas a partir do contato e da proximidade com ele. Subjetividade que é sempre resposta, substrato que, na sua passividade, responde como responsabilidade pelo Outro, entretecida na sensibilidade como vulnerabilidade da subjetividade, ao mesmo tempo como fruição e sofrimento e não como representação e pensamento.

\section{À GUISA DE CONSIDERAÇÕES FINAIS: DO GIRO ÉTICO À PROBLEMATIZAÇÃO POLÍTICA}

Que efeitos poderiam ter este tipo de pensamento na compreensão das relações éticas tecidas nos contextos escolares? Trata-se de uma questão que permanece aberta e que exige de nós, educadores, um esforço na busca por respostas. Desdobrando esta questão em outras, também perguntamos, que ressonâncias poderiam ter uma filosofia da alteridade na formação de um profissional, como a professor, que é essencialmente relacional? A escola é um local de encontro com o rosto do Outro ou um local em que este Outro é constantente assediado a submeter-se, a ser dominado, a ser assimilado? As políticas educacionais, especialmente as que se desenham nesse novo panorama político brasileiro, são políticas que levam em consideração o Outro ou são políticas que desprezando a alteridade, desprezam também o diálogo?

Se não há diálogo, há a solidão de um poder que se exerce através de ordens, de comandos e da tentativa de submeter o Outro através de um monólogo do "mesmo" enfeitiçado consigo. Traduzindo-se em políticas públicas que não reconhecem a alteridade do professor e da sociedade civil organizada e que não quer ouvir, talvez porque tenha um secreto medo desse Outro que não é reconhecido em sua alteridade, mas que deve obedecer e se submeter aos ditames do mesmo.

\section{REFERÊNCIAS}

ANDRADE, R.C.L. Formação Moral e Educação: um estudo a partir da filosofia prática de Kant. Marília, 2013. Tese de doutorado. Universidade Estadual Paulista, 2013.

CARVALHO, A. B. Razão e Paixão: Necessidade e contingência na construção da vida ética. Conjectura, v. 17, n. 1, p. 199-217, jan./abr. 2012.

GADAMER, H.-G. O problema da consciência histórica. Trad.: Paulo Cesar Duque Estrada. Fundação Getúlio Vargas Ed.: Rio de Janeiro, 1996.

KANT, Immanuel. Crítica da Razão Pura. Trad. e notas de Fernando Costa Mattos. Petrópolis, RJ: Vozes; Bragança Paulista, SP: Editora Universitária São Francisco, 2012a.

Resposta à pergunta: Que é esclarecimento? (Auflkarung) Trad. Floriano de Souza Fernandes. In: KANT, I. Textos Seletos. 8a edição. Petrópolis, RJ: Vozes, 2012b, p. 63-71.

Começo conjctural da história humana. Trad. Edmilson Menezes. São Paulo, SP:

Editora Unesp, 2010. 
LEVINAS. E. Totalidade e Infinito. Trad. José Pinto Ribeiro. Lisboa: Ediçoes 70, 1980. . Linguagem e Proximidade. In: Descobrindo a existência com Husserl e Heidegger. Lisboa: Inst. Piaget, 1998.

MATEO, M.S. Razón y sensibilidad em la ética de Kant. Tucuman (Argentina): 1981.

MIRANDA, J.V.A. A sensibilidade ética em Emmanuel Levinas. Kínesis, Vol. III, nº 06, p. 170-183, Dez. 2011.

MOYSES NETO. O ingovernável (BLOG). Disponível em: https://moysespintoneto.wordpress.com. Acesso em 17 ago 2018.

PEREIRA, J.A. Crítica de Levinas ao sujeito moral de Kant. Polymatheia, Vol. IV, no 5, p.99-111, 2009. 